\title{
DESTRUCTIVE WAVE OVERTOPPING AND WAVE RUN-UP TESTS ON GRASS COVERED SLOPES OF REAL DIKES
}

Gosse Jan Steendam ${ }^{1}$, Yvo Provoost ${ }^{2}$ and Jentsje van der Meer $^{3}$

\begin{abstract}
In March 2011 new wave overtopping tests have been performed in the Netherlands. In contrast to previous tests the grass cover of this dike was not maintained well, which had significant effect on erosion stability. Additionally, for the first time a pilot test has been made on wave run-up from an asphalt berm onto the grass covered upper slope of the dike. The tested dike sections had a sand core covered by a layer of clay and a grass cover. The objective was to test the erosion stability of seaward and landward slopes for wave overtopping as well as wave run-up. For the wave overtopping also the influence on erodibility of the grass cover caused by obstacles or other elements, which may be present at dikes (stairs, fences), was investigated.
\end{abstract}

Keywords: Wave overtopping; wave run-up, wave overtopping simulator; testing on real dikes

\section{WAVE OVERTOPPING TESTS}

In 2011, following previous tests from 2007 to 2010 (Steendam et al. 2008, 2010 and 2011), wave overtopping tests have been performed in the Netherlands on a dike near Tholen (Figure 1). The objective of these tests was to evaluate the performance of a bad grass cover on the slope subjected to loads by overtopping waves. A second objective of these tests was to evaluate the performance under overtopping wave loads of stairs and a fence on the landward slope. At the site also a section was present which was rehabilitated as it was damaged during reconstruction works. This section was tested under loads of wave overtopping as well as wave run-up and wave run down (Van der Meer et al., 2012).

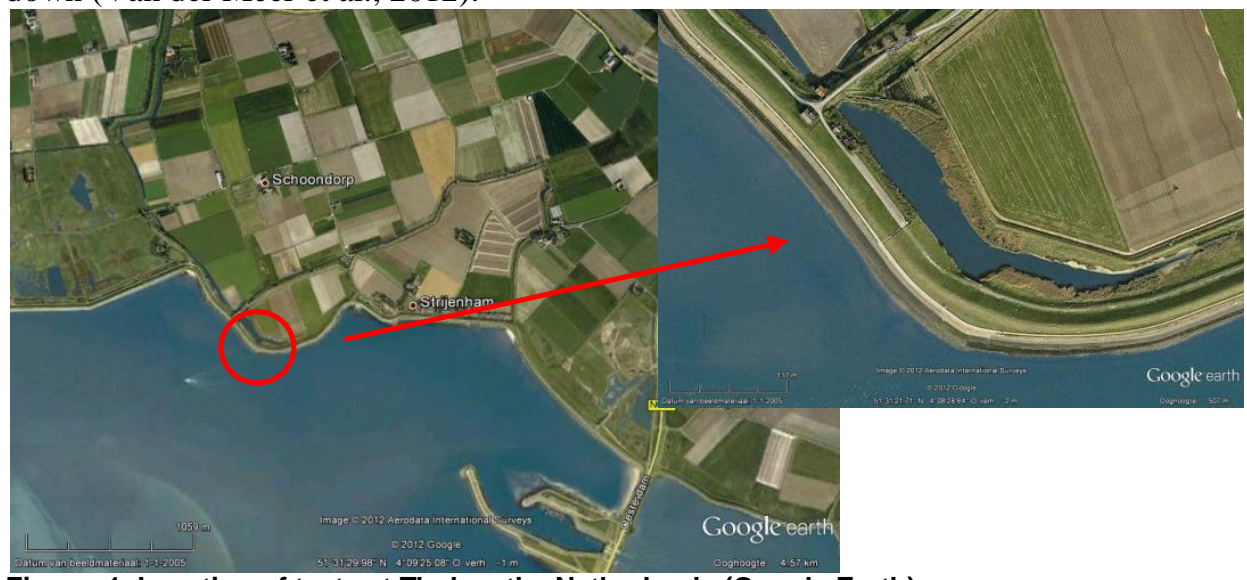

Figure 1. Location of tests at Tholen, the Netherlands (Google Earth).

In Figure 2 the test sections are shown.

\section{Landward}

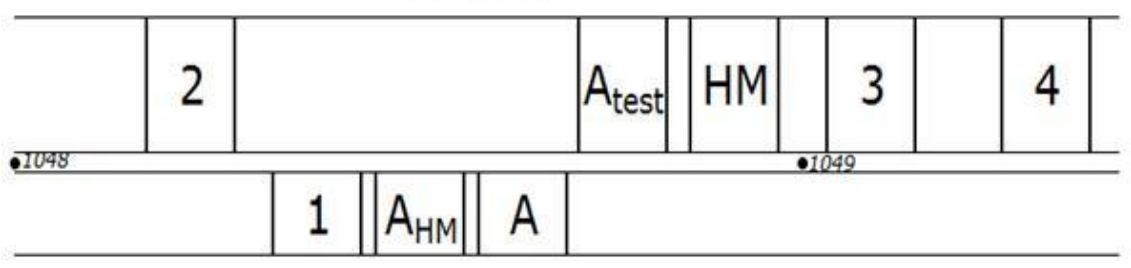

\section{Seaward}

Figure 2. Lay out of the test sections

\footnotetext{
${ }^{1}$ INFRAM B.V., P.O. Box 16, 8316 ZG, Marknesse, the Netherlands. Gosse.Jan.Steendam@INFRAM.nl

${ }^{2}$ Projectbureau Zeeweringen, Rijkswaterstaat, P.O. Box 1000, 4330 ZW, Middelburg, the Netherlands. Yvo.Provoost@rws.nl

${ }^{3}$ Van der Meer Consulting, P.O. Box 423, 8440 AK, Heerenveen, the Netherlands. im@vandermeerconsulting.nl
} 
All sections have been tested with the Wave Overtopping Simulator (Van der Meer et al. 2006, 2008) on a $4 \mathrm{~m}$ wide stretch, flanked by guidance walls. The Wave overtopping Simulator was, in wave overtopping tests, placed just in front of the crest in order to also test the crest itself. In the case of the wave run-up test the simulator was placed at the lower end of the berm.

The tested sections are listed in Table 1, see also Figure 2.

Table 1 Test sections and their main objective

\begin{tabular}{|l|l|l|l|}
\hline Test section & Object of test & Slope & DP \\
\hline 1 & Excavated area, wave overtopping test & seaward & $1048+69,7 \mathrm{~m}$ \\
\hline 2 & stairs & landward & $1048+59,9 \mathrm{~m}$ \\
\hline 3 & fence & landward & $1049+5,8 \mathrm{~m}$ \\
\hline $\mathrm{HM}$ & hydraulic measurements overtopping & landward & $1048+94,6 \mathrm{~m}$ \\
\hline 4 & reference test & landward & $1049+19,0 \mathrm{~m}$ \\
\hline $\mathrm{A}_{\text {test }}$ & calibration wave run-up test & landward & $1048+87,1 \mathrm{~m}$ \\
\hline $\mathrm{A}_{\mathrm{HM}}$ & $\begin{array}{l}\text { hydraulic measurements }+ \text { calibration run- } \\
\text { up test }\end{array}$ & seaward & $1048+75,7 \mathrm{~m}$ \\
\hline $\mathrm{A}$ & Excavated area, wave run-up test & seaward & $1048+81,7 \mathrm{~m}$ \\
\hline
\end{tabular}

The tests performed were destructive observation tests. This means that the hydraulic loads induced on the slopes were by no means the design conditions for the dike itself. Each of the tests was performed with increasing loads due to increasing mean overtopping discharges, ranging from 1 to 75 1/s per $\mathrm{m}$. Each sub-test was performed for 6 hours. The test with 1 1/s per $\mathrm{m}$ was speeded up 5 times because only 150 waves overtop in 6 hours, corresponding to the distribution as formulated in EurOtop Manual, 2007 and Van der Meer et al. 2011. The wave parameters used to calculate the volumes in the overtopping waves in the tests (in random order released) were a significant wave height $\mathrm{H}_{\mathrm{s}}=2 \mathrm{~m}$ and a spectral wave period $\mathrm{T}_{\mathrm{m}-1,0}=5.8 \mathrm{~s}$.

The tests were performed on to differently managed alignments. The first, in which test sections 1 and 2 were situated, the management and maintenance consisted of grazing by sheep in summertime, no fertilizer and no addition of herbicides. Actually it turned out the management was not done as it should have. It was found to be over-grazed, also in winter, with very short grass leaves. The second alignment, in which sections 3 and 4 are located, was managed as a lawn. Four times a year the grass was flail mown.

Figure 3 shows a typical cross section of the dike. The dike itself consists of a sand core covered with a clay layer. This clay layer varied al lot in thickness.

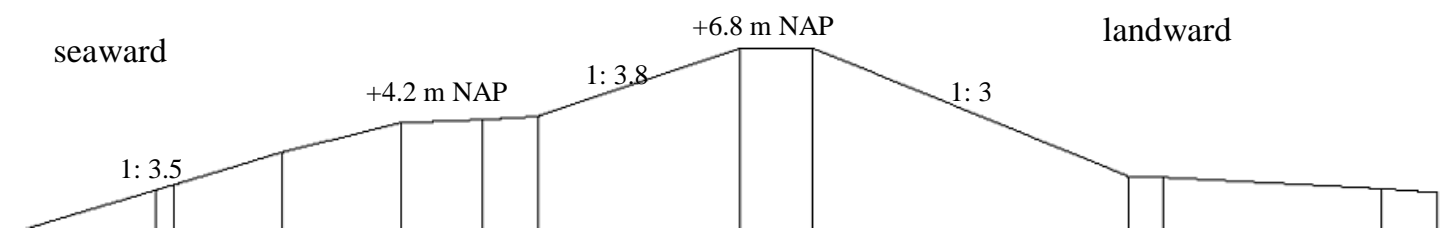

Figure 3 Cross section at test location

\section{Observations and analyses per test section}

In the next sections a description of the tests performed will be given. Next to that an brief analysis will be made on the observed damage and failure mechanisms. The critical velocity of the dike sections will be determined by using the method of cumulative hydraulic overload. This method is described in Van der Meer et al. 2010. This cumulative hydraulic overload is a measure for the damage or erosion of the landward slope of a dike. With this method a damage number is determined by considering the number of waves and the flow velocity of the largest wave volumes from observations after the experiments. In Deltares, 2012 the methodology is extended for transitions from landward slopes to berms and trees/piles on the landward slope. The original formulation was: 
With:

$$
\sum_{i=1}^{N}\left(U^{2}-U_{c}^{2}\right)=D
$$

$\mathrm{U}=$ depth-averaged flow velocity $(\mathrm{m} / \mathrm{s})$

$\mathrm{U}_{\mathrm{c}}=$ critical depth-averaged flow velocity $(\mathrm{m} / \mathrm{s})$

$\mathrm{D}=$ damage parameter $\left(\mathrm{m}^{2} / \mathrm{s}^{2}\right)$

$\mathrm{N}$ = number of overtopping waves exceeding $\mathrm{U}_{\mathrm{c}}(-)$

Based on results from previous tests the following damage criteria are defined (Van der Meer et al. 2010):

Initial damage

Damage at various locations

Failure of dike slope

$$
\begin{gathered}
\mathrm{D}<500 \mathrm{~m}^{2} / \mathrm{s}^{2} \\
500 \mathrm{~m}^{2} / \mathrm{s}^{2}<\mathrm{D}<1.500 \mathrm{~m}^{2} / \mathrm{s}^{2} \\
\mathrm{D}>3.500 \mathrm{~m}^{2} / \mathrm{s}^{2}
\end{gathered}
$$

It should be noted that the first two definitions (initial damage and damage at various locations) vary a lot in damage number. Only failure of the dike slope is fairly constant, using a correct critical velocity. This formulation yields for slopes. At real dikes a lot of objects are present which are not intended to contribute to the strength of the dike. These objects are for example stairs, buildings, fences, etc. But also transitions from slope to horizontal proved to be more vulnerable to damage than the slope itself. Therefore in Deltares, 2012 the cumulative hydraulic overload method is extended to:

$$
\sum_{i=1}^{N}\left(\left(\alpha_{M} U^{2}\right)-U_{c}^{2}\right)=D
$$

In the cumulative hydraulic overload method now an amplification factor $\alpha_{M}$ is added. In fact this factor increases the actual velocity or load compared to the velocity over the slope without transition or object. Actually overtopping waves with lower velocities will cause damage to occur earlier than on the slope. This amplification factor is chosen to keep the method clear. In fact decreasing the critical velocity at transitions or objects may be a similar approach. Nevertheless in the cumulative overload method it is assumed that the critical velocity does not change for a given slope, but the hydraulic load increases.

By taking this amplification factor into account more waves will contribute to initiation and progress of damage at or around objects or transitions as $\alpha_{M}$ is larger than 1. From previous tests it is learned that the amplification factor ranges roughly between 1.1 and 1.25. For the tests in this paper an amplification factor $\alpha_{M}=1.21$ was found.

\section{Section 1: Rehabilitated slope}

In test section 1 the seaward slope of the dike was tested. Of course at this slope overtopping is not the mechanism which in reality at severe storms is induced. At this side wave impact and wave runup/down will cause the loads. The reason behind the choice to assess the seaward slope was the fact that this slope was excavated during replacement of the block revetment at the lower slope of the dike one year before. The contractor needed space for his equipment to replace the blocks. Therefore he excavated approximately one meter of the upper slope as is indicatively shown in Figure 4.

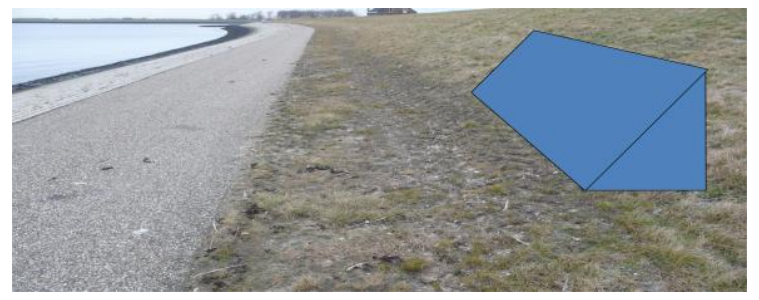

Figure 4 Excavated part of the seaward slope (for maintenance block revetment lower end of slope)

At first glance at the test section it became clear that there was hardly any grass coverage at the part that was rehabilitated after the excavation one year ago. Figure 5 shows the setup of the test. 


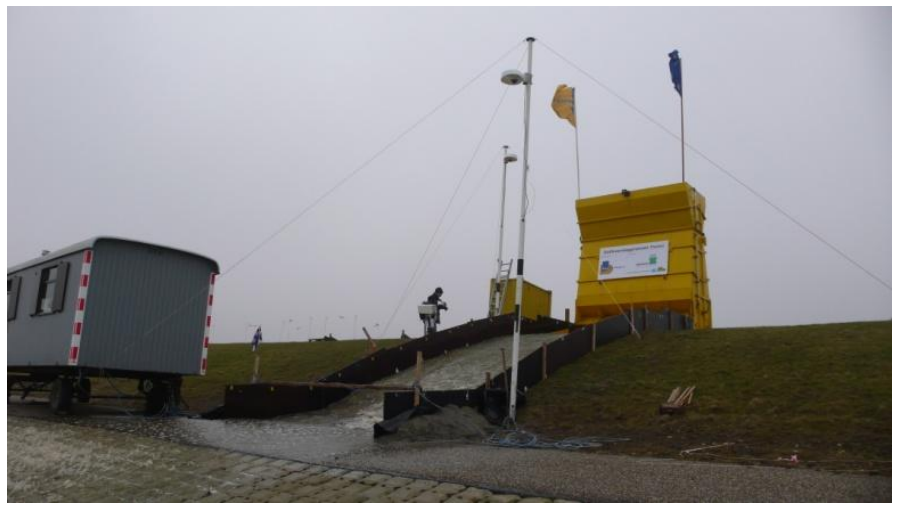

Figure 5 Set up test section 1

Tests were performed with a mean overtopping discharge of 1 (duration of 1 hour and 12 minutes representing 6 hours of storm), 10 (6 hours) and 30 1/s per m (1 hour). After the tests with 1 and 10 l/s per $\mathrm{m}$ no significant damage occurred. Only some minor bold spots appeared on the slope. At the toe some minor damage was observed. Small erosion holes up to a maximum depth of $0.2 \mathrm{~m}$ had developed between the toe and the asphalt slab. The already poor vegetation had disappeared even more. After some large waves in the test with $30 \mathrm{l} / \mathrm{s}$ per $\mathrm{m}$ it was found that the asphalt slab moved up and down. An undermining of the asphalt occurred. Some of the water flowed underneath the asphalt slab. The test was terminated because of the fear of large damage of the asphalt berm. The purpose of the test was to evaluate the strength of the rehabilitated section of the slope. This part did experience some minor progress in the last hour of the test at the berm from the toe to the asphalt slab. This progress consisted of erosion on average of a few centimeters of the surface. The end result of the test is shown in Figure 6.

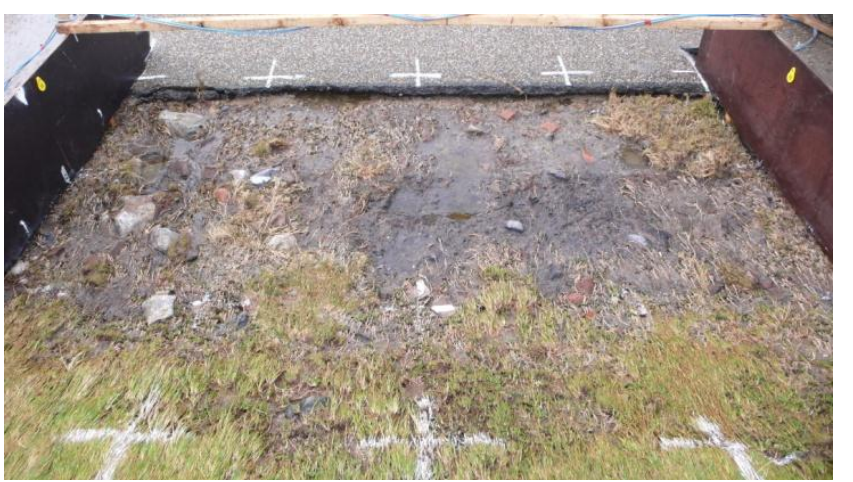

Figure 6. Final result of overtopping test section 1; various damaged locations (photo taken from the slope down)

Already from the start of the test it was seen that a lot of debris was present at the rehabilitated part of the slope and the berm. See also results of the wave run-up test further down this paper. It is believed that only large waves contribute to erosion damage. In this test and also in earlier tests it is seen that the wave fronts initiate erosion. The flow of water then provides a means of transport for the soil or other parts which are loosened by the impact of the wave front. This is one of the mechanisms which initiates damage and leads to progress of damage. In Van der Meer et al. 2010 the method of cumulative hydraulic overload was presented. The results of this test are quantified with this method and an indication of the critical velocity for this part of the slope was found to be around 4 or $5 \mathrm{~m} / \mathrm{s}$.

Section 2. Influence of stairs on erodibility of grass covered landward slope

In the second section the objective was to evaluate the influence of the stairs on the erodibility of the grass covered slope.

Figure 7 shows the setup of the test. 

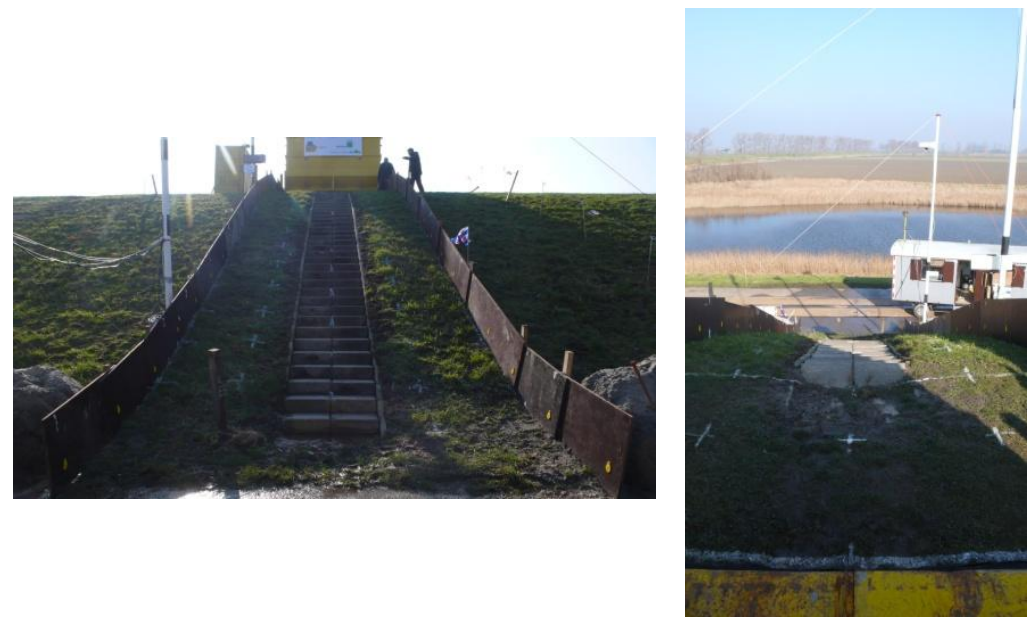

Figure 7 Set up of test section 2 (left from below and right from top)

The stairs at this location were used by many people as it is a popular diving spot. The intense use of the stairs was also seen at the crest. The grass there was trampled upon intensively and the coverage showed large bold spots (see also right part of Figure 7) and declined areas. From the last steps towards the crest underneath some $10 \mathrm{~cm}$ of soil a pitched stone path was present. This seemed up front a possible weak spot. Therefore the crest was part of the test. It also was seen that there was a very poor or no connection of the grass cover with the stairs. Evidence of use of pesticides to prevent grass from growing over the stairs was found. This use of pesticides leads to almost no vegetation direct near the concrete stairs. The soil was found to be loose in that area. The slope itself was walked on quite intensively. Evidently people tend not to use the steps but walk on the slope just alongside the stairs to the crest of the dike. The grass cover therefore showed a poor coverage with large open spots. The average slope became more gentle from the toe up. The lower part was 1:2 going up to 1:3 at the top part of the slope.

Already from the start with a mean overtopping discharge of $1 \mathrm{l} / \mathrm{s}$ per $\mathrm{m}$ strong erosion started alongside the stairs. At the end of this test already a hole of $0.5 \mathrm{~m}$ had formed next to the stairs. Also at the toe, the transition from the stairs to the asphalt berm, the grass cover had eroded. As this was not

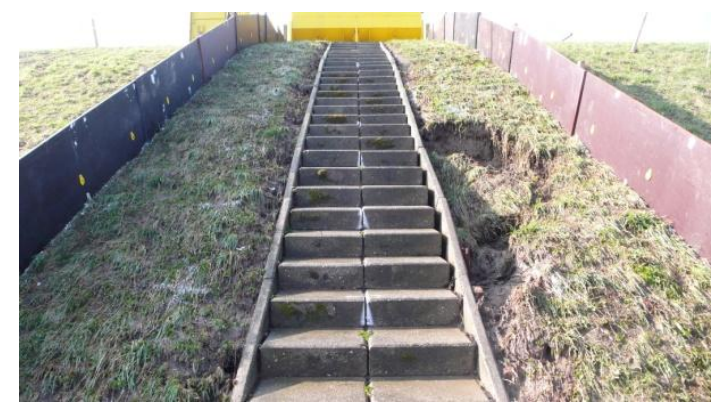

Figure 8 Failure of slope section 2 the objective of this test this part was reinforced and covered. In this test it was also noticed that water rushed through holes of moles leading to wider openings and water flowing out at the toe. This increased with the increase of mean discharge to $5 \mathrm{l} / \mathrm{s}$ per $\mathrm{m}$. Slowly the stairs and the grass cover were undermined. After 2 hours the grass cover failed as it collapsed in the erosion hole (Figure 8). With each overtopping wave the damage increased and after 4 hours the stairs collapsed as it then was undermined heavily (Figure 9). 


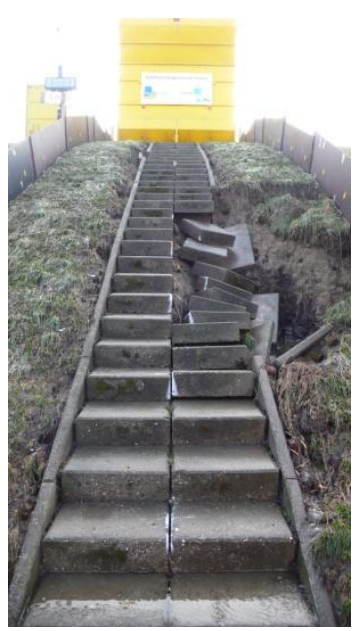

Figure 9. Failure of stairs, section 2
After the collapse the test went on. Figure 10 shows the end result. With each overtopping wave the damage grew and the stairs were undermined more leading to collapse of more steps. Also at the slope the damage increased steadily.

As the slope degraded next to the stairs, the damage at the holes of moles was of minor importance.

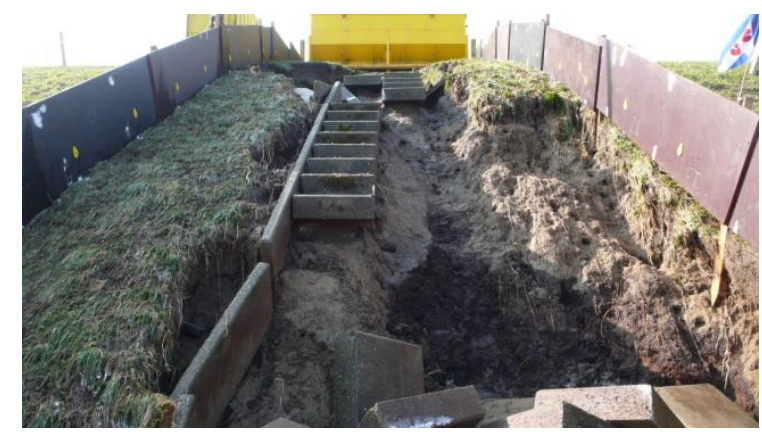

Figure 10. Destruction of stairs

It is of no use to assess the critical velocity of this slope with the stairs as it would be found that this was very low or even zero. Every overtopping wave leads to initiation and increase of damage. Therefore it is absolutely intolerable to allow this dike section to overtop in extreme conditions.

Section 3. Influence of fence on erodibility of grass covered landward slope

In the test program also a slope with a fence perpendicular to the crest was incorporated. The slope was very irregular and showed dents and small damages. A couple of mole tunnels were present. In one occasion the mole heap consisted of sand material. At the bottom of the fence a heap was present with a height of $0.2 \mathrm{~m}$ in average. On this heap rugged vegetation which withered away was present. With 5 1/s per m overtopping waves rushed through a tunnel of a mole. With the water coming out of the hole also sand came out, leading to a sand containing well some $5 \mathrm{~m}$ below the point of entrance.

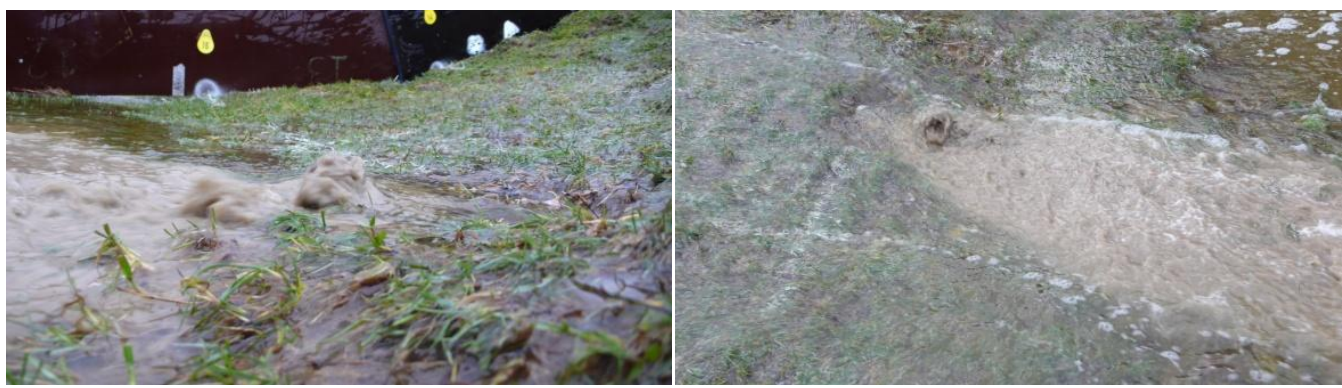

Figure 11. Sand containing well through tunnel of mole

After an hour testing a subsidence on the slope became visible. The water and sand rushing out became larger and larger. At a certain point the section where the outflow was, lifted. This phenomenon has been seen before at earlier tests (Steendam, 2008) and was called the "bulge out" mechanism (Figure 12). After each wave the bulge went down as the water flushed out.
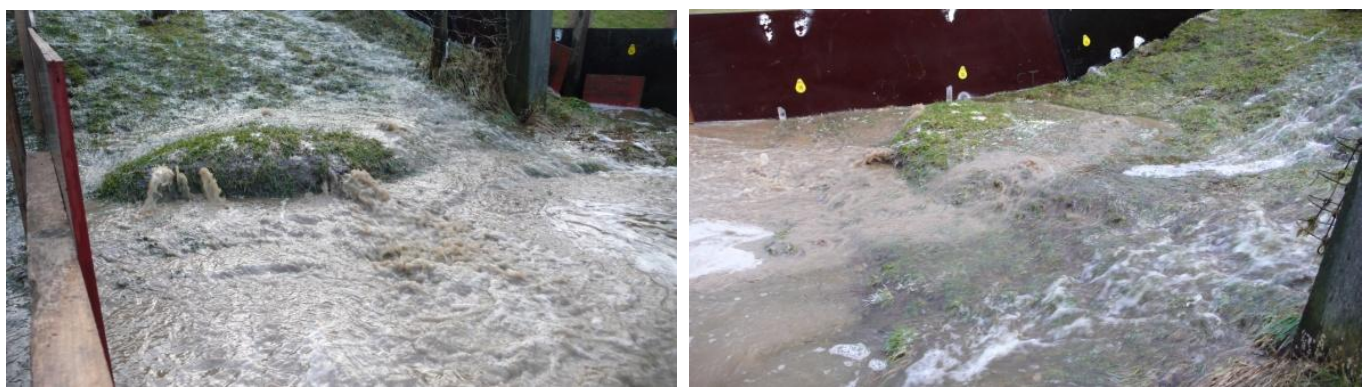

Figure 12. "Bulge out" mechanism before and after the water has flown out 
Apparently the grass sod with its root system is strong enough to hold together as water rushes in the hole under the bulge. With each overtopping wave some of the roots at the edges break. The sod becomes weaker and weaker until with a large wave the forces get too large and the sod comes loose at one end and breaks off a little later. The test still was performed with a mean overtopping discharge of only $5 \mathrm{l} / \mathrm{s}$ per $\mathrm{m}$.
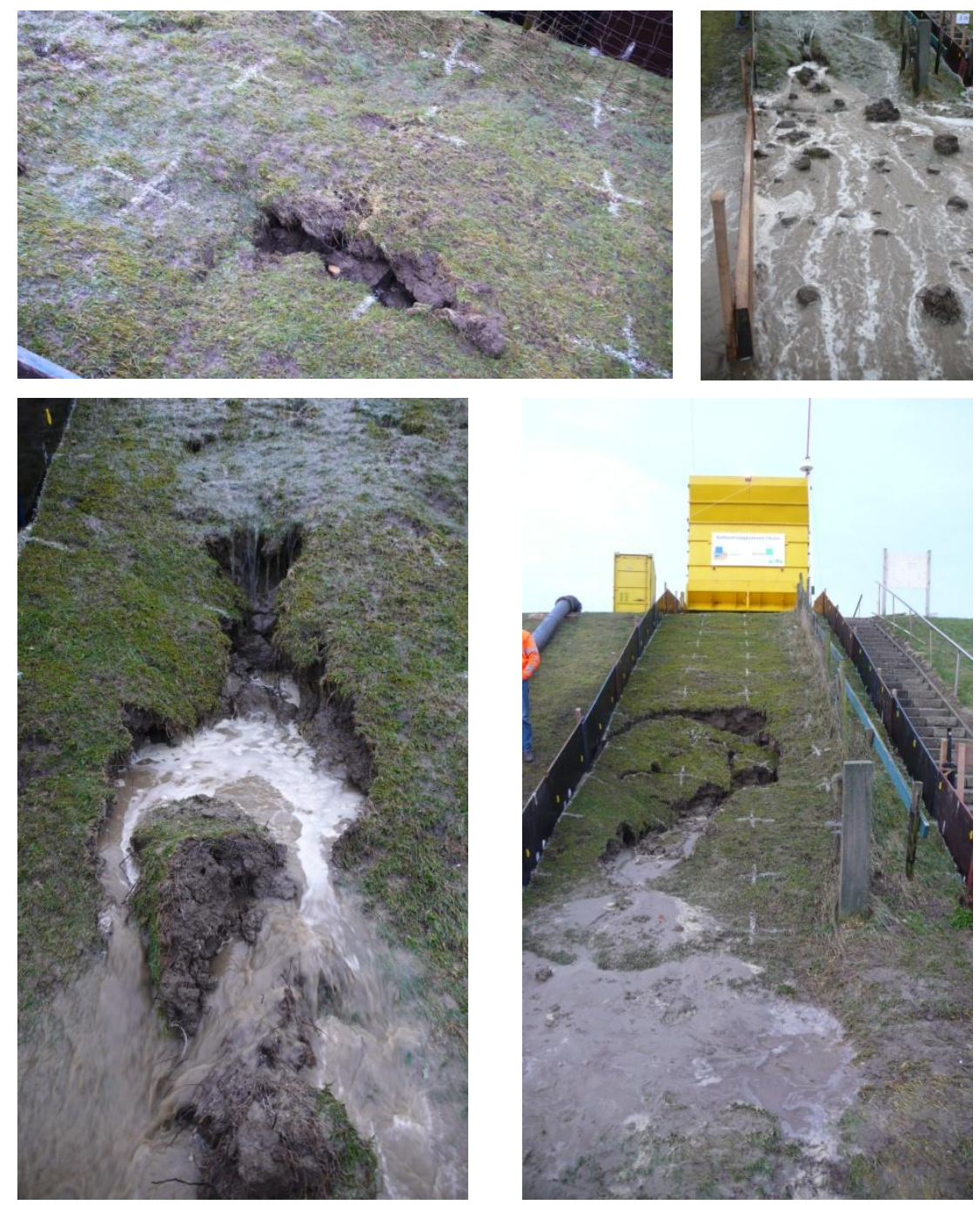

Figure 13. Consequent steps leading from "bulge out" mechanism to failure of slope section 3

The grass cover at this slope was investigated before testing. It was found to be very weak as is was very uneven, showed large open areas, had a cover containing a lot of mosses and showed damage by moles and damage by some mechanical force (tracks of hydraulic crane). This was consistent of what was found in the test. It is obvious that the critical velocity of this slope is very low. Every overtopping wave will contribute to damage on the slope. Therefore no overtopping at all must be allowed at this dike under design conditions.

The object of this test was, besides the slope itself, the fence. At the stage where the slope failed no damage was present at all at the fence. The damage on the slope was repaired and was covered up. As testing went on some superficial erosion occurred some $0.3 \mathrm{~m}$ from the fence due to contraction of flow. This contraction occurred because the flow split as it encountered the elevated surface at the bottom of the fence. The test went on to $501 / \mathrm{s}$ per $\mathrm{m}$.

At the lower end of the slope across the maintenance road a pole of $0.2 \mathrm{~m}$ wide was present. At $10 \mathrm{l} / \mathrm{s}$ per $\mathrm{m}$ scour occurred around this pole. At $30 \mathrm{l} / \mathrm{s}$ per $\mathrm{m}$ this scour hole seemed to have reached an equilibrium depth of $0.6 \mathrm{~m}$. No further increase of depth was found at $50 \mathrm{l} / \mathrm{s} \mathrm{per} \mathrm{m}$. 


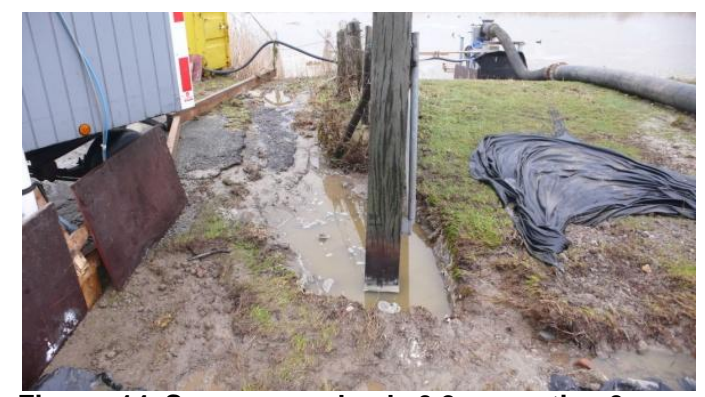

Figure 14. Scour around pole $0.2 \mathrm{~m}$, section 3

Section 4 reference test

To verify the findings of section 3 a reference test was performed in section 4 . Again the grass cover was inspected beforehand. Again it was found to have a very irregular surface. Also here a lot of mole activity was found and the slope was grazed heavily (short grass) and had large open (bold) areas. Due to a lot of mosses the surface seems at first glance well covered. In some heaps of moles (a lot of) sand was found.

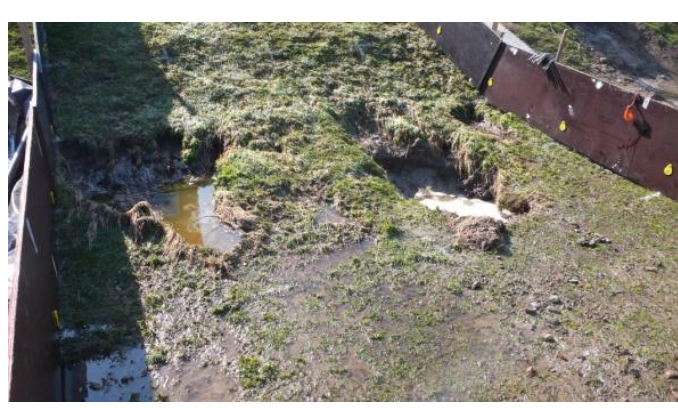

Figure 15. Damage at toe up to core of the dike, section 4

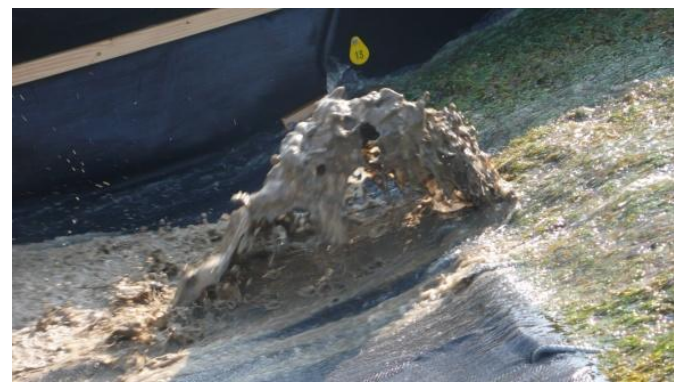

After 6 hours of $5 \mathrm{l} / \mathrm{s}$ per $\mathrm{m}$ only minor erosion of entrances of mole tunnels was found. Also some more, but still minor damage at the toe was seen. This latter damage grew to serious damage or even failure when testing went on with $10 \mathrm{l} / \mathrm{s}$ per m. After 4 hours and 45 minutes the test was terminated as the damage at the toe reached the sand of the core of the dike.

The toe of the dike was not the main objective of the test. Therefore again the damage was covered up and testing went on on the slope.

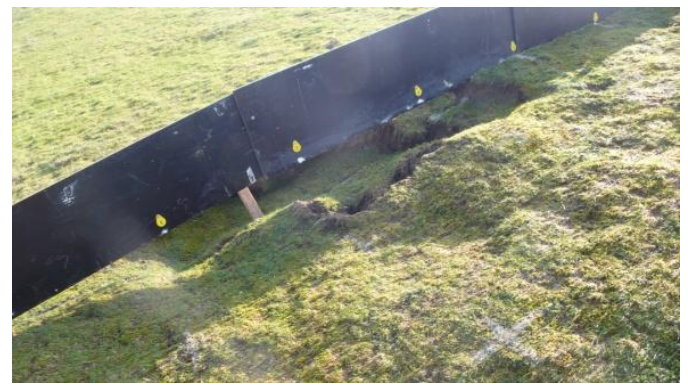

Figure 16 .Left: Water and sand flushing out tunnel of mole. Right subsidence of slope

At $30 \mathrm{l} / \mathrm{s}$ per $\mathrm{m}$ it was found that there again was a tunnel of a mole through which water with sand was transported to the toe of the dike. This lead to a lot of sand near the toe and a subsidence higher on the slope. As a result of the large quantity of sand flushed out from the slope a large hole occurred. At a certain moment the grass cover broke. To prevent extensive damage to happen the test was terminated. The mechanism that lead to failure was exact the same as found in section 3 , but now at a little larger mean overtopping discharge.

Evaluation of the test section with the cumulative hydraulic overload method leads to an indication of critical velocity for this slope around $4 \mathrm{~m} / \mathrm{s}$. As shown the toe of the dike failed in an earlier stage. With the cumulative hydraulic overload method with the amplification factor it is found that $\alpha_{M}=1.21$. This means that if the actual front velocity in a certain overtopping wave is over $3.3 \mathrm{~m} / \mathrm{s}$ this wave contributes to initiation and progression of damage. As almost every overtopping wave at sea conditions will have a velocity over $3 \mathrm{~m} / \mathrm{s}$ it is again proven that it is absolutely not safe to allow this dike to be overtopped at design conditions.

From the tested sections it can be observed and/or concluded that:

- In relation to previous tests a new failure mechanism was found: flushing out of sand of the core of the dike through holes made by moles. The holes penetrated through the cover layer of grass and 
clay on to the sand core and back to the surface, creating a tunnel through which sand could be transported. Eventually the surface subsided and damage started (sliding of the cover layer). A main reason for this failure mechanism was the presence of a bad grass cover, which could not add to the strength against overtopping erosion.

- Stairs prove to be sensible to very early damage as the connection between the stairs and the adjacent grass cover was actually not present due to an error (using pesticides) in daily maintenance. This can lead to very early damage and failure of the dike section.

- A fence perpendicular to the crest on the landward side of the dike proved not to be a weak spot (please note that also the waves were perpendicular to the dike crest).

- At the overtopping tests on a grass cover and a transition to an asphalt berm, the asphalt cover was pushed up by water pressures underneath the asphalt.

- Again it was found that an obstacle on the slope with dimensions larger than $0.15 \mathrm{~m} \times 0.15 \mathrm{~m}$ may lead to excessive erosion around this object when overtopping waves hit that obstacle and cause concentration of currents.

- Transitions from slope to berm are again proven to be weak spots.

The main conclusion of the tests was that a good grass cover may give significant strength against overtopping erosion, but a bad grass cover gives actually no strength at all and should be considered as an unprotected clay layer.

\section{HYDRAULIC MEASUREMENTS}

From the start of the tests with the Wave Overtopping Simulator in 2007 attempts have been made to measure flow velocities and thickness of the flow at the crest and over the slope of the dike. This measuring proved to be very difficult as the instruments available at that time were not suitable for the job. The main reason for failure of the instruments was lack of robustness and other conditions than what the instruments were designed for. Large turbulence and air content, relative high velocities and shape of loads (sudden impact of the water tongue and the distribution of water mass in the tail) caused failures of the instruments. To measure velocities and thicknesses of the water flowing over the crest and slope new instruments have been developed over time. These instruments are simple and robust. To measure flow thickness a surfboard was developed. This curved board floats on top of the passing water tongue. The rotation of the board at the hinge is measured and with the calibration data the shape of the overtopping wave, the thickness of the water tongue, can be determined.

Flow velocities can be measured with high speed camera's. The captured speed than is the velocity of the front of the wave over a certain part of the slope. No distribution or shape of the changing velocity in the passing water tongue in time nor in the vertical can be determined. From 2010 experiments were made with paddle wheels. These paddle wheels rotate with the moving water. Every rotation gives a pulse and therefore the velocity of the passing wave can be measured over time. The paddle wheels were placed in the surf board and at a plate on the slope. From first tests it was found that the velocity just several centimeter above the plate was the same as higher in the vertical, meaning that the boundary of the overtopping water was just a few centimeters.

Following measurements with the new simple an robust devices at the Vecht dike in 2010 (Van der Meer et al., 2010; Steendam et al., 2010) new measurements have been made at tests in Tholen in 2011.

At the Vecht dike a gentle slope 1:3.7 at the upper part of the slope changing to a 1:5.2 slope at the down part was present. At Tholen a much steeper slope of 1:2.4 was present.

At the Vecht dike no measurements were made at the horizontal crest of the dike just in front of the release of the Wave Overtopping Simulator. At force measurements in Belgium (Steendam et al, 2011) records were made on a flat and horizontal area. During these tests forces were measured on a vertical wall impacted by simulated overtopping waves.

From the measured data from the tests at the Vecht dike it was found that the velocity of the overtopping water did not vary much along the slope and the following relations were found from the recorded data:

$$
\begin{gathered}
h=0.133 V^{0,5} \\
u=5.0 V^{0,34}
\end{gathered}
$$

With:

$$
\begin{aligned}
& \mathrm{h}=\text { thickness of water tongue }(\mathrm{m}) \\
& \mathrm{V}=\text { volume of overtopping wave }\left(\mathrm{m}^{3}\right)
\end{aligned}
$$


$\mathrm{u}=$ flow velocity

$(\mathrm{m} / \mathrm{s})$

The setup of the devices for hydraulic measurements at the dike at Tholen is shown in Figure 17 and Figure 18, with "PW" for paddle wheels and "SB" for surfboard:

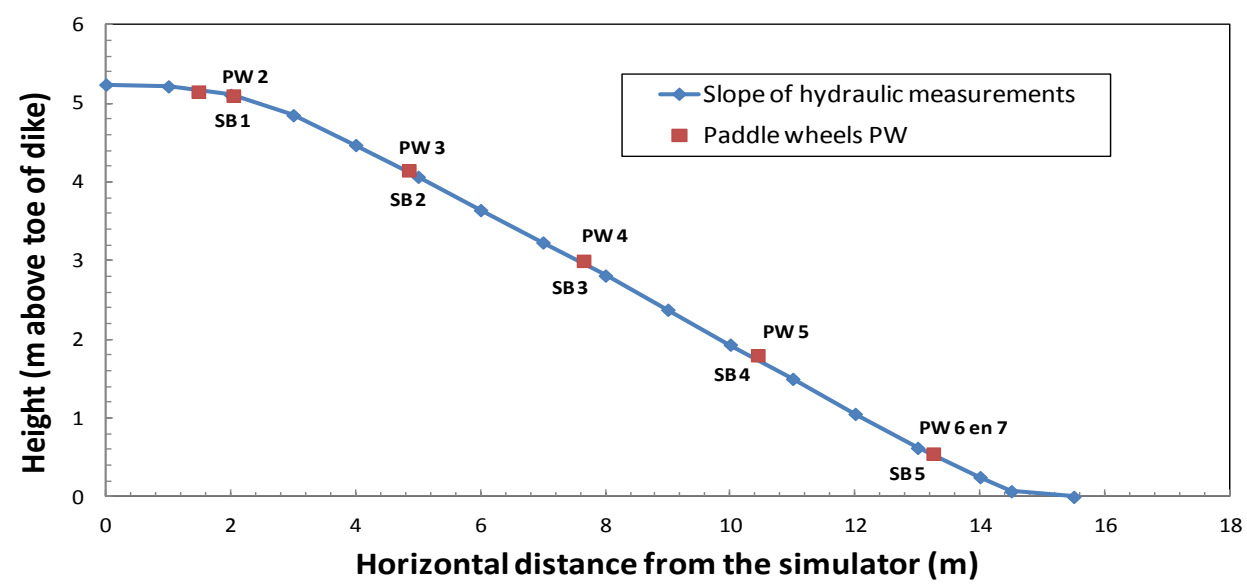

Figure 17. Setup of hydraulic measurements

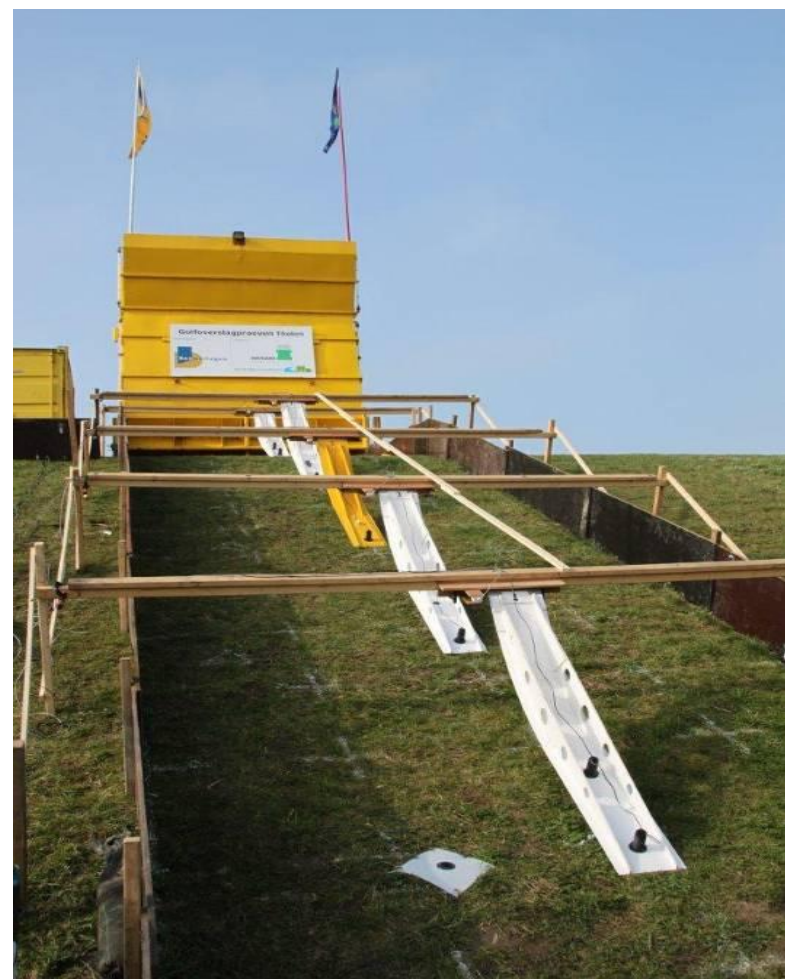

In total 7 paddle wheels for measuring velocities and 5 surfboards for measuring flow depths were installed.

Paddle wheels (PW) 1 and 2 were located on the crest whereas Paddle wheels (PW) 3 to 7 were located on the slope. All Paddle wheels were placed on the surf board except for paddle wheel (PW) 7. Paddle wheel (PW) 7 was placed on a plate on the slope.

Paddle wheels (PW) 1 and 2 were placed on the same surf board. The reason for this was that the elevation of the surf board differs a lot with each released volume. If the elevation becomes too high the paddle wheel may be released from the water. By placing a second wheel higher up in the surf board the maximum velocities will be measured correctly. For small volumes the first paddle wheel will measure correctly.

Figure 18. Overall view of devices at hydraulic measurements 
Figure 19 shows the results of the measurements with the paddle wheels. Equation (4) determined with the Vecht dike measurements has also been plotted in this figure (blue line).

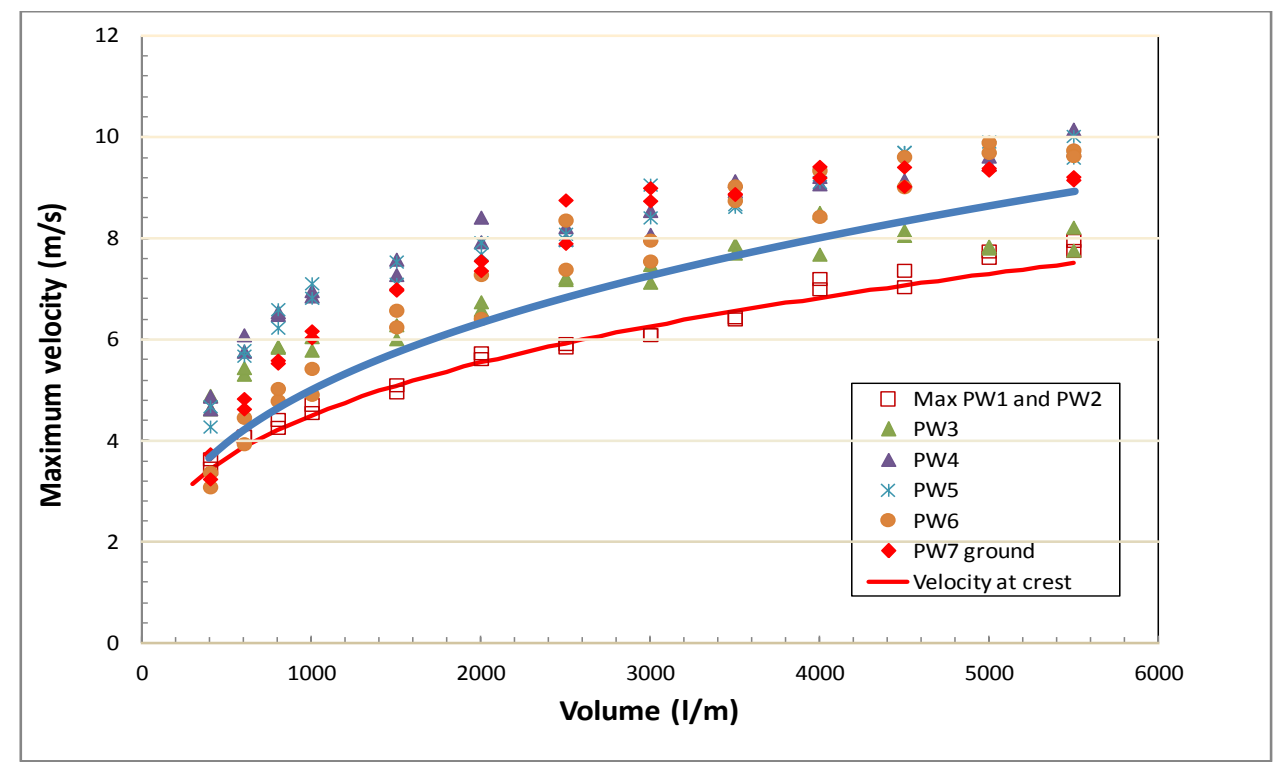

Figure 19. Results of velocity measurements

Figure 19 shows the maximum velocities measured at different locations along the slope. The trendline of the Vecht dike is taken as an average along the slope $(4,8$ and $12 \mathrm{~m}$ from the inner landward crest line). At the Vecht dike the maximum velocity along the slope seemed not to change as the water moved down. In Figure 19 it can be seen that on the slope in Tholen the velocity increases along the slope. In contrast with the Vecht dike the slope is much steeper.

Analysis of the data of Tholen shows that the velocity at the crest of the dike can be described as:

$$
u=4.5 V^{0,30}
$$

\section{WAVE RUNUP}

The section used for the wave run-up test was on the seaward side from the asphalt berm upwards to the crest of the dike. The setup of the tests is shown in Figure 20. This was a pilot test never performed before. 


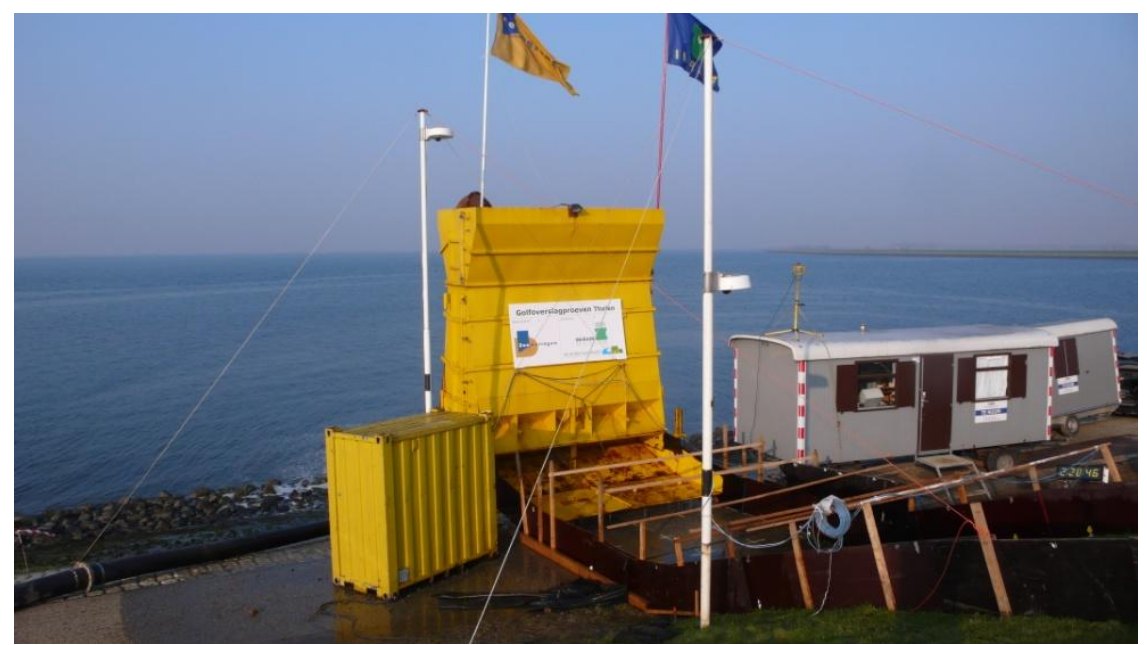

Figure 20. Setup Wave run-up test

The theory behind the wave run-up test performed by the wave overtopping simulator is described in Van der Meer, 2011 and Van der Meer et al., 2012.

With run-up a velocity must be simulated at a certain spot on the seaward slope and then the wave must run up to a certain wave run-up level (Van der Meer et al., 2012). The wave run-up height usually is represented by the height which is reached by $2 \%$ of the incoming waves, $\mathrm{Ru}_{2} \%$.

The tests simulated an increase in water level against the dike at which the waves run up higher and higher. The level which was reached by $2 \%$ of the waves therefore also reached higher at each new test. The wave run-up simulator stayed at the same level throughout all tests.

This pilot test on wave run-up was executed successfully. The result of this first test was that now new information for further development of a wave run-up simulator was gathered. It was also indicated that the method of cumulative hydraulic overload, now being developed for wave overtopping, may also be used for wave loads induced by wave run-up (Van der Meer, 2011, and Van der Meer et al. 2012).

A total of 5 tests were performed. De hydraulic wave conditions simulated were $\mathrm{H}_{\mathrm{s}}=2 \mathrm{~m}$ and $\mathrm{T}_{\mathrm{p}}=$ $5.7 \mathrm{~s}$. The simulator was not moved during the tests. The simulated water level increased with each test and were measured vertically beneath the berm (distance $\mathrm{x}$ ). The berm level is defined as the level of the outflow of the device.

The test results were as follows:

- Only small surface erosion was noticed for tests with a water level of $4.5 \mathrm{~m}$ and $4.0 \mathrm{~m}$ below the outflow opening ( $\mathrm{z}_{2} \%$ just below or on level of outflow).

- A first small erosion hole at the transition from berm to upper slope, about $7 \mathrm{~cm}$ deep, was noticed after 2 hours with $\mathrm{x}=3.2 \mathrm{~m}\left(\mathrm{z}_{2} \% 0.8 \mathrm{~m}\right.$ above outflow opening). After the full test there were three small erosion holes each about $7 \mathrm{~cm}$ deep. This damage is close to the criterion of "several open spots".

- Damage increased during the next tests. The test was stopped after 4 hours with $\mathrm{x}=1.6 \mathrm{~m}\left(\mathrm{z}_{2} \% 2.4\right.$ $\mathrm{m}$ above outflow opening). A cliff had been formed at three holes at the transition from berm to upper slope with a height of about $0.5 \mathrm{~m}$. The upper slope had not yet failed, see Figure 21 , but the test had to be terminated as problems with the side boards (large hydraulic loads) led to unwanted effects. 


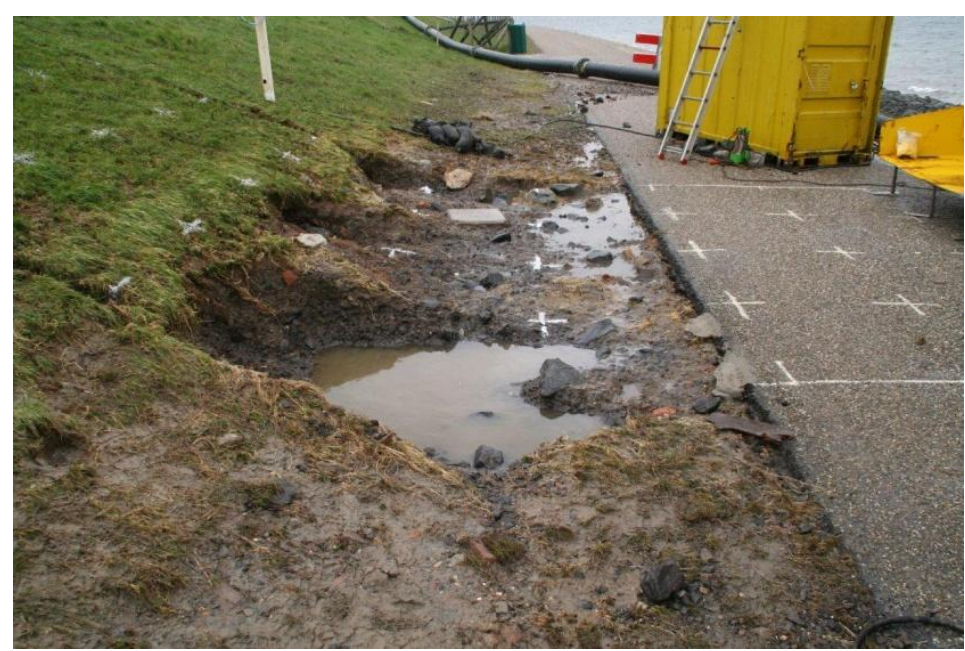

Figure 21. Final damage after the pilot run-up test.

For a critical velocity of $u_{c}=5 \mathrm{~m} / \mathrm{s}$ as well as $6 \mathrm{~m} / \mathrm{s}$ "start of damage" or "several open spots" was noticed well below the values of $\Sigma\left(u^{2}-u_{c}{ }^{2}\right)=500 \mathrm{~m}^{2} / \mathrm{s}^{2}$ and $1000 \mathrm{~m}^{2} / \mathrm{s}^{2}$, which were determined from overtopping tests. But for the wave overtopping tests it was also concluded that these values had very large deviations. Sometimes start of damage occurred very far before failure, sometimes start of damage and failure were very close. As the area around the transition had not much vegetation, but only a good quality clay, some superficial erosion could be expected for fairly low hydraulic loads.

The slope did not fail, however, there was still quite a reserve capacity. With a total cumulative overload of $1249 \mathrm{~m}^{2} / \mathrm{s}^{2}$ for a critical velocity of $u_{c}=6 \mathrm{~m} / \mathrm{s}$ it is well below the level for failure of $\Sigma\left(\mathrm{u}^{2}-\mathrm{u}_{\mathrm{c}}^{2}\right)=3500 \mathrm{~m}^{2} / \mathrm{s}^{2}$.

Above analysis leads to the following conclusions:

- The cumulative overload method can be applied for wave run-up, but the main difference with wave overtopping is that a specific location on the slope should be chosen. The cumulative overload reduces for locations higher up the slope, where the loads on the inner slope of a dike by wave overtopping are fairly constant along the slope.

- The velocities simulated during the pilot run-up tests are equal or lower than the required velocities. For a good simulation of the run-up process larger velocities should be simulated, but also different velocities for more or less similar run-up levels. This might be achieved by a different (more slender) shape of the simulator and by steering the opening (rotation) of the valve.

- Start of damage and "several open spots" were observed for fairly low hydraulic overloads, mainly as superficial erosion of the clay with minor vegetation. These damage levels for wave overtopping have always been unpredictable.

- The best predictable measure is "failure" with $\Sigma\left(\mathrm{u}^{2}-\mathrm{u}_{\mathrm{c}}^{2}\right)=3500 \mathrm{~m}^{2} / \mathrm{s}^{2}$. Using $\mathrm{u}_{\mathrm{c}}=6 \mathrm{~m} / \mathrm{s}$ gives a total cumulative overload for the whole test of $\Sigma\left(u^{2}-u_{c}^{2}\right)=1249 \mathrm{~m}^{2} / \mathrm{s}^{2}$. This is well below the value for failure, which was also the description of the final status of the slope after testing.

- This analysis shows that the method of cumulative overload can be applied to wave run-up. There is, however, not enough validation to conclude that the same cumulative damage values have to be used as for wave overtopping to describe the behavior of the slope. More testing on run-up is required to come to final conclusions.

- It is also found that run-down did not cause any damage as there still was a layer of water present on the slope.

\section{REFERENCES}

Deltares. 2012. SBW Wave overtopping and grass cover strength, model development, 1206016-007

Steendam G.J., P. Peeters, J.W. van der Meer, K. van Doorslaer and K. Trouw. 2011. Destructive wave overtopping tests at Flemish dikes, Proceedings Coastal Structures, Yokohama, Japan

Steendam, G.J., J.W. van der Meer, B. Hardeman and A. van Hoven. 2010. Destructive wave overtopping tests on grass covered landward slopes of dikes and transitions to berms, Proceedings International Conference on Coastal Engineering, Shanghai, China, ASCE. 
Steendam, G.J., J.W. van der Meer, G. de Raat, W. de Vries and J.Y. Frissel. 2008. Influence of Management and Maintenance on erosive impact of wave overtopping on grass covered slopes of dikes. Proceedings International Symposium on Floodrisk, Oxford, United Kingdom.

Van der Meer, J.W., Y. Provoost and G.J. Steendam. 2012. The wave run-up simulator, theory and first pilot test, Proceedings International Conference on Coastal Engineering, Santander, Spain, ASCE.

Van der Meer, J.W., 2011. The Wave Run-up Simulator. Idea, necessity, theoretical background and design. Van der Meer Consulting Report vdm11355.

Van der Meer, J.W., B. Hardeman, G.J. Steendam, H. Schüttrumpf and H. Verheij. 2010. Flow depths and velocities at crest and inner slope of a dike, in theory and with the Wave Overtopping Simulator, Proceedings International Conference on Coastal Engineering, Shanghai, ASCE. China.

Van der Meer, J.W., W. Snijders and E. Regeling. 2006. The wave overtopping simulator, Proceedings International Conference on Coastal Engineering, San Diego, United States, ASCE.

Van der Meer J.W., G.J. Steendam, G. de Raat and P. Bernadini. 2008. Further developments on the wave overtopping simulator. ASCE. Proc. ICCE 2008, Hamburg, Germany. 